that cross sexual transmission increases severity (unpublished observations). Hence, the effect may be related to viral infections. We previously suggested that virus may take sex determinants from host cells, causing those produced in male and female hosts to be different.' This could facilitate infection of cells in individuals of the opposite sex. Alternatively, virus from someone of the same sex may be controlled more easily by the immune system. From this perspective it is important to test whether the association between cross sexual transmission and increased severity of disease is limited to viral infections or whether it is a more general phenomenon of infections transmitted directly between humans. Animal studies or laboratory experiments also seem warranted to examine the role of cross sexual transmission in severity of infection.

This study was supported by the Muséum National d'Histoire Naturelle, the Institut National d'Etudes Demographiques, the Centre National de la Recherche Scientifique (UA 49), the Institut National de la Santé et de la Recherche Médicale, and the Office de la Recherche Scientifique et Technique Outre-Mer. PA received support from the Danish Councils for Development Research, Medical Research, and Social Science Research. We thank the Ministère du Plan et de la Coopération and the Ministère de la Santé, Sénégal, for their agreement, interest, and help in our work; Sophie Auger, Josette Benaben, Francoise Branson, Sara Camara, Mamadou-Yero Diallo, Catherine Enel, Danièle Fouchier, Mussa Kebe, Kili Keita, André Langaney, Maria Ramirez, and Lampa Sadiaho, who participated or helped in collecting and coding the data.
1 Aabv P, Bukh J, Lisse IM, Smits AJ. Cross-sex transmission of infection and increased mortality due to measles. Rev Infect Dis 1986;8:138-43.

2 Pison G, Langaney A. The level and age pattern of mortality in Bandafass (Eastern Senegali: results from a small-scale and intensive multi-round survey. Population Studies 1985;39:387-405.

3 Pison G. Dynamique d'une population traditionelle: les Peul Bandé (Sénégal Oriental). Paris: Presse Universitaires de France, 1982.

4 Pison G, Bonneuil N. Increased risk of measles mortality for children with siblings among the Fula Bande, Senegal. Rev Infect Dis 1988;10:468-70.

5 McCullagh P, Nelder JA. Generalized linear models. New York: Chapman and Hall, 1983.

6 McGregor IA. Measles and child mortality in the Gambia. West Afr Med f 1964;13:251-7

7 Aaby P. Malnourished or overinfected. An analysis of the determinants of acute measles mortality. Dan Med Bull 1989;36:93-113.

8 Aaby P, Leeuwenburg J. Patterns of transmission and severity of measles infection. A reanalysis of data from the Machakos area, Kenya. $\mathcal{F}$ Infect Dis 1990;161:171-4.

9 Garenne M, Aaby P. Pattern of exposure and measles mortality in Senegal. IInfect Dis 1990;161:1088-94.

10 Aaby $\mathrm{P}$, Molbak K. Siblings of opposite sex as a risk factor for child mortality. BMF 1990;301:143-5.

11 Babbott FL, Gordon JE. Modern measles. Am f Med Sci 1954;228:334-61

12 Bhuiya A, Woityniak B, D'Souza S, Nahar L, Shaikh K. Measles case fatality among under-fives: a multivariate analysis of risk factors in a rural area of Bangladesh. Soc Sci Med 1987;24:439-43.

13 Aaby P, Bukh J, Lisse IM, Smits AJ. Risk factors in subacute sclerosing panencephalitis (SSPE): age-and sex-dependent host reactions or intensive exposure. Rev Infect Dis 1984;6:239-50.

14 Fargues P, Nassour O. Douze ans de mortalité urbaine au Sahel. Paris: Presses Universitaires de France, 1988

15 Monastiri $\mathrm{H}$. Quelques données statestiques relatives a la mortalité par rougeole dans la Commune de Tunis. La Tunisie Medical 1961;39:179-87.

16 Aaby P. Severity of measles and cross-sex transmission of infection in Copenhagen, 1915-1925. Int f Epidemiol 1991;20:504-7.

17 A Copenhagen, 1915 , Leeus A reanalysis of data from the Machakos area, Kenva. Ann Trop Paediatr (in press).

18 Aaby P, Lamb WH. Sex and transmission of measles in a Gambian village. f Infect 1991;22:287-92.

(Accepted 13 November 1991
(Medical Research Council,) Biostatistics Unit, Cambridge

S-M Gore, PHD, medical statistician

\section{World Health}

Organisation, Diarrhoeal

Disease Control

Programme, 1211 Geneva

27, Switzerland

O Fontaine, MD, medical

officer

N F Pierce, MD, medical

officer

Correspondence to: Dr

Fontaine.

BM7 1992;304:287-91

\title{
Impact of rice based oral rehydration solution on stool output and duration of diarrhoea: meta-analysis of 13 clinical trials //
}

\author{
Sheila MGore, Olivier Fontaine, Nathaniel F Pierce
}

\section{Abstract}

Objective-To define the benefit of rice oral rehydration salts solution in relation to the glucose based World Health Organisation oral rehydration salts solution for treating and preventing dehydration in patients with severe dehydrating diarrhoea.

Design-Meta-analysis using data from 13 available randomised trials that compared these two formulations.

Subjects-The studies compared 1367 patients with cholera, severe cholera-like diarrhoea, or acute non-cholera diarrhoea. 668 received the standard WHO solution and 699 the rice based solution.

Intervention-Each trial report was reviewed to determine patient eligibility, the number of patients who were randomised and the number of these excluded from analysis, details of the randomisation procedure, and the precise timing of the outcome measurements.

Main outcome measures-Stool output during the first 24 hours; weighted estimates of the difference in mean stool output between treatments.

Results - The rice solution significantly reduced the rate of stool output during the first 24 hours by $36 \%(95 \%$ confidence interval 28 to $44 \%)$ in adults with cholera and by $32 \%$ (19 to $45 \%$ ) in children with cholera. The rate of stool loss in infants and children with acute non-cholera diarrhoea was reduced by only $18 \%$ ( 6 to $30 \%)$.

Conclusions - The benefit of rice oral rehydration salts solution for patients with cholera is sufficiently great to warrant its use in such patients. The benefit is considerably smaller for children with acute, non- cholera diarrhoea and should be more precisely defined before its practical value can be judged.

\section{Introduction}

Oral rehydration therapy with the glucose and electrolyte solution recommended by the World Health Organisation and Unicef is the preferred method for treating children with dehydration due to diarrhoea, provided that they are able to drink and do not have signs of shock.' Although the solution is both safe and effective (D Mahalanabis, unpublished WHO document), it has important limitations: it neither reduces the rate of stool loss nor shortens the duration of illness. ${ }^{2.5}$ Mothers often do not understand the relation between diarrhoea and dehydration, and their primary concern, shared by many health workers, is to see the diarrhoea stop. This probably accounts for the continuing widespread use of ineffective "antidiarrhoeal" drugs and antibiotics to treat diarrhoea instead of, or in addition to, oral rehydration salts solution (WHO diarrhoeal diseases control programme, seventh programme report, 1988-89, 1990).

If a packaged oral rehydration salts formulation could be developed that not only had the positive features of the WHO formulation, including low cost and safety and stability during prolonged storage, bu also substantially reduced the duration of diarrhoea or the rate of stool loss, it would have considerable advantages. In particular, it could be promoted as having a real antidiarrhoeal effect. This should improve its acceptance and use by both health workers and mothers, especially if its benefits were sufficiently great 
to be evident to them. It might also result in less use of ineffective drugs and antibiotics. Such changes would represent a major advance in efforts to control morbidity and mortality associated with diarrhoea through effective case management.

Several clinical trials have shown that an oral rehydration salts solution containing cooked rice powder $(50-80 \mathrm{~g} / \mathrm{l})$ in place of the usual glucose $(20 \mathrm{~g} / \mathrm{l})$ substantially reduces the rate of stool loss due to acute diarrhoea. ${ }^{6-10}$ Other studies, however, have reported no significant benefit. ${ }^{11-14}$ The subjects in these studies varied considerably and included infants, children, and adults both with diarrhoea associated with cholera and with acute diarrhoea not associated with cholera. Moreover, in some studies the number of patients evaluated was probably insufficient to support firm conclusions. To define more precisely the true benefit of rice oral rehydration salts solution in relation to the WHO oral rehydration salts solution and to determine whether this benefit is related to the patient's age or the aetiology of diarrhoea we performed a meta-analysis by using data from all available randomised clinical trials that compared these two formulations.

\section{Methods \\ SELECTION OF TRIALS}

Studies included in this overview were identified by a computer aided search of the published work, by reviewing the references cited in relevant reports, and by inquiring about completed but unpublished studies from our colleagues. Ten published reports ${ }^{6.15}$ and three unpublished ones (A M Moechtar, E Guiraldes, and $\mathrm{N} \mathrm{H}$ Alam, personal communications) were identified and are reviewed in this analysis. On the basis of their design or method of analysis these 13 studies yielded 17 comparisons between patient groups treated with rice oral rehydration salts or the WHO oral rehydration salts solution. Table I gives the principal features of each comparison. In all cases the studies were randomised trials that compared standard WHO oral rehydration salts solution with an experimental oral rehydration salts solution in which glucose $(20 \mathrm{~g} / \mathrm{l})$ was replaced by $50-80 \mathrm{~g} / 1$ of rice powder, the electrolyte concentrations remaining unchanged. In early studies (A N Alam, personal communication $)^{8-11} 13-15$ the rice powder was cooked immediately before use and salts were added after the rice solution had cooled. In the most recent ${ }^{612}$ (Moechtar et al, Guiraldes et $a$ ) a commercially produced, precooked rice powder was prepackaged with oral rehydration salts, in sachets to make up one litre. This was

TABLE I-Characteristics of randomised trials of rice oral rehydration solution

\begin{tabular}{|c|c|c|c|c|c|}
\hline Comparison & Age & Dehydration & $\begin{array}{l}\text { Cholera (proportion } \\
\text { proved on culture) }\end{array}$ & $\begin{array}{l}\text { Amount of rice in } \\
\text { solution }(g / 1)\end{array}$ & $\begin{array}{l}\text { No randomised to } \\
\text { WHO/rice solution } \\
\text { (No excluded) }\end{array}$ \\
\hline \multicolumn{6}{|c|}{ Patients with cholera or cholera-like illness } \\
\hline $\begin{array}{l}\text { Moechtar } \\
\text { et al }(1)^{\star}\end{array}$ & $>12$ years & Severe & Yes & 50 & $83 / 81(0 / 0)$ \\
\hline Moechtar & & & & & \\
\hline et al $(2)^{\star}$ & $>12$ years & Severe & No & 50 & $12 / 14(0 / 0)$ \\
\hline Alam et al (1)† & Adults & Moderate to severe & Yes & 50 & $47 / 46(?)$ \\
\hline Alam et al (2) $\dagger$ & Adults & Moderate to severe & Yes & 50 & 42/47(?) \\
\hline Molla et al $(1)^{\star \star \star}$ & $>10$ years & Moderate to severe & Yes $(65 \%)$ & 80 & $74 / 85(2 / 0)$ \\
\hline Molla et al $(2)^{x \star}$ & $?-<10$ years & Moderate to severe & Yes $(75 \%)$ & 80 & $105 / 84(4 / 0)$ \\
\hline Molla et al (3) & $1-5$ years & Moderate to severe & Yes $(55 \%)$ & 50 & $42 / 37$ (?) \\
\hline $\operatorname{Molla}(4)^{?}$ & $2-5$ years & Moderate to severe & Yes $(80 \%)$ & 80 & $25 / 27(0 / 0)$ \\
\hline Alam $(3)^{4 \star}$ & $1-8$ years & Moderate to severe & Yes $(100 \%)$ & 50 & $19 / 20(2 / 2)$ \\
\hline Alam $(4)^{4 \star}$ & $1-8$ years & Moderate to severe & No & 50 & $7 / 6(0 / 0)$ \\
\hline Patra $e t a l^{b}$ & 3 months -5 years & Moderate to severe & Yes $(30 \%)$ & 50 & $26 / 26(2 / 2)$ \\
\hline \multicolumn{6}{|c|}{ Patients without cholera } \\
\hline Guiraldes et al & 4-24 months & Moderate & No & 50 & $49 / 51(1 / 2)$ \\
\hline Kenya et al ${ }^{14}$ & 4-59 months & Moderate to severe & No & 60 & $50 / 51(1 / 1)$ \\
\hline Dutta et $a l^{12}$ & 4 months -4 years & Moderate & No & 50 & $33 / 37(0 / 0)$ \\
\hline Bhan $e t a l^{\prime \prime}$ & 3 months -5 years & Moderate & No & 50 & $33 / 31(0 / 0)$ \\
\hline El Mougi et als & 4-18 months & Moderate & No & 50 & $30 / 30(4 / 5)$ \\
\hline Mohan $e t a l^{13}$ & 3 months -3 years & Mild to severe & No & 50 & $24 / 26(1 / 3)$ \\
\hline
\end{tabular}

$\star$ Single studies in which results were stratified for analysis. tClinical trial with a factorial design ( 4 cell trial). prepared for use in the same way as standard WHO oral rehydration salts, as precooked rice dissolves rapidly in cold water.

To our knowledge no other randomised trials of these formulations of rice oral rehydration salts solution have been completed, although several are underway. We have not included three trials of solutions that contained only $30 \mathrm{~g} / \mathrm{l}$ of rice powder (O Fontaine, personal communication $)^{12} 16$ and one of an oral rehydration salts solution containing rice powder and glycine. ${ }^{17}$

Each trial report was reviewed independently by a statistician (SMG) and a clinician (OF) to determine patient eligibility according to stated selection criteria for age and dehydration status; the number of patients who were randomised and the number of these subsequently excluded from analysis; details of the randomisation procedure; and the precise timing of the outcome measurements, such as stool output and intake of oral rehydration salts solution.

\section{META-ANALYSIS}

Each of the 17 comparisons yielded an estimate of the true difference in mean stool output between patients treated with the two different salts solutions; and each difference in means $\left(D_{i}\right.$ for comparison $\left.i\right)$ is qualified by a variance:

$$
\operatorname{var}\left(D_{i}\right)=\left(s_{i}\right)^{2}
$$

The larger the variance, the less precise is the observed difference as an estimate of the true difference in mean stool output between treatment groups. It follows that the amount of information conveyed by a single comparison about this true difference is inversely proportional to the variance of the estimated difference for that comparison. If the inverse of the variance is taken as a measure of the information contained in comparison $\mathrm{i}$, then the weight $\left(\mathrm{w}_{\mathrm{i}}\right)$ that should be accorded to comparison i, among all comparisons in its set, may be taken to be the information in comparison $i$ divided by the total information (that is, the sum over all comparisons $i=1,2, \ldots n$ of the inverse of the variances):

$$
\mathrm{w}_{\mathrm{i}}=\left[\left(1 / \mathrm{se}_{\mathrm{i}}\right)^{2}\right] / \sum_{\mathrm{i}=1}^{\mathrm{n}}\left(1 / \mathrm{se}_{\mathrm{i}}\right)^{2}
$$

Clearly, these weights add up to one. A pooled or weighted estimate of the difference in mean stool output between patients treated with rice oral rehydration salts solution or WHO oral rehydration salts solution is obtained by summing the differences in individual comparisons, each multiplied by its corresponding weight, so that if a single comparison accounts for $10 \%$ of the information then $10 \%$ of its estimated difference counts towards the pooled estimate. With the foregoing choice of weights, the variance of the pooled difference has a particularly simple form. Just as we defined information as the inverse of variance, so the variance of the pooled estimate is the inverse of the total information:

$\operatorname{var}($ pooled difference $)=\operatorname{var} \sum_{i=1}^{n} w_{i} D_{i}=1 / \sum_{i=1}^{n}\left(1 / s_{i}\right)^{2}$

A $95 \%$ confidence interval for the pooled estimate runs from two standard errors below the pooled estimate to two standard errors above, where the standard error is the square root of the variance of the pooled estimate.

\section{Results}

EVALUATION OF TRIALS

The review identified problems in both the design and the analysis of some trials. These are summarised below.

\section{Randomisation}

The randomisation of patients should have occurred 


\begin{tabular}{|c|c|c|c|c|c|c|}
\hline \multirow[b]{2}{*}{ Comparison } & \multirow[b]{2}{*}{$\begin{array}{l}\text { No analysed taking } \\
\text { WHO/rice solution }\end{array}$} & \multicolumn{3}{|c|}{ Treatment with WHO solution } & \multirow[b]{2}{*}{$\begin{array}{l}\text { Mean reduction (variance) } \\
\text { in stool output during } \\
\text { treatment with rice } \\
\text { solution }(\mathrm{g} \mathrm{or} \mathrm{ml} / \mathrm{kg})\end{array}$} & \multirow[b]{2}{*}{ Study weight } \\
\hline & & $\begin{array}{l}\text { Mean (SD) stool } \\
\text { output (g or ml/kg } \\
\text { in first } 24 \mathrm{~h})\end{array}$ & $\begin{array}{l}\text { Mean stool } \\
\text { output/SD }\end{array}$ & $\begin{array}{l}\text { Mean stool output/ } \\
\text { mean intake of } \\
\text { solution }\end{array}$ & & \\
\hline Moechtar et al (1) 6-24 hours & $83 / 81$ & $133(92)$ & 1.4 & 0.63 & $39(148)$ & 0.45 \\
\hline Moechtar et al (2) 6-24 hours & $12 / 14$ & $106(55)$ & 1.9 & 0.63 & $48(407)$ & $0 \cdot 16$ \\
\hline Alam et al (1) & $47 / 46$ & $391(157)$ & $2 \cdot 5$ & $0 \cdot 75$ & $164(829)$ & 0.08 \\
\hline Alam et al (2) & $42 / 47$ & $366(174)$ & $2 \cdot 1$ & 0.81 & $144(1068)$ & 0.06 \\
\hline Molla et al $(1)^{x}$ & $72 / 85$ & $159(109)$ & 1.5 & 0.64 & $44(266)$ & $0 \cdot 25$ \\
\hline
\end{tabular}

TABLE III - Stool output in first 24 hours in children with diarrhoea associated with cholera or cholera-like illness

\begin{tabular}{|c|c|c|c|c|c|c|}
\hline \multirow[b]{2}{*}{ Comparison } & \multirow[b]{2}{*}{$\begin{array}{l}\text { No analysed taking } \\
\text { WHO/rice solution }\end{array}$} & \multicolumn{3}{|c|}{ Treatment with WHO solution } & \multirow{2}{*}{$\begin{array}{l}\text { Mean reduction (variance) } \\
\text { in stool output during } \\
\text { treatment with rice } \\
\text { solution }(\mathrm{g} \text { or } \mathrm{ml} / \mathrm{kg} \text { ) }\end{array}$} & \multirow[b]{2}{*}{ Study weigh } \\
\hline & & $\begin{array}{l}\text { Mean (SD) stool } \\
\text { output (g or ml/kg } \\
\text { in first } 24 \mathrm{~h} \text { ) }\end{array}$ & $\begin{array}{l}\text { Mean stool } \\
\text { output/SD }\end{array}$ & $\begin{array}{l}\text { Mean stool output/ } \\
\text { mean intake of } \\
\text { solution }\end{array}$ & & \\
\hline Molla et al $(2)^{x}$ & $101 / 84$ & $204(140)$ & $1 \cdot 5$ & 0.54 & $49(362)$ & $0 \cdot 42$ \\
\hline Molla et al (3)" & $42 / 37$ & $343(151)$ & $2 \cdot 3$ & 1.49 & $181(628)$ & Zero \\
\hline Molla et al (4) & $25 / 27$ & $210(158)$ & $1 \cdot 3$ & 0.69 & $105(1206)$ & $0 \cdot 12$ \\
\hline Alam et al $(3)^{4 \star}$ & $19 / 20$ & $290(190)$ & 1.5 & 0.98 & $160(2500)$ & 0.06 \\
\hline Alam et al $(4)^{4 \star}$ & $7 / 6$ & $90(75)$ & $1 \cdot 2$ & 0.57 & $-40(700)$ & $0 \cdot 21$ \\
\hline Patra et $a l^{*}$ & $24 / 24$ & $166(114)$ & 1.5 & $0 \cdot 62$ & $69(794)$ & $0 \cdot 19$ \\
\hline
\end{tabular}

${ }^{\star}$ Data not reported quantitatively; values in this table are approximated from graphic presentation.

TABLE IV -Stool output in first 24 hours in children with diarrhoea not associated with cholera

\begin{tabular}{|c|c|c|c|c|c|c|}
\hline \multirow[b]{2}{*}{ Comparison } & \multirow[b]{2}{*}{$\begin{array}{l}\text { No analysed taking } \\
\text { WHO/rice solution }\end{array}$} & \multicolumn{3}{|c|}{ Treatment with WHO solution } & \multirow[b]{2}{*}{$\begin{array}{l}\text { Mean reduction (variance) } \\
\text { in stool output during } \\
\text { treatment with rice } \\
\text { solution }(\mathrm{g} \text { or } \mathrm{ml} / \mathrm{kg})\end{array}$} & \multirow[b]{2}{*}{ Study weigh } \\
\hline & & $\begin{array}{l}\text { Mean (SD) stool } \\
\text { output }(\mathrm{g} \text { or ml/kg } \\
\text { in first } 24 \mathrm{~h})\end{array}$ & $\begin{array}{l}\text { Mean stool } \\
\text { output/SD }\end{array}$ & $\begin{array}{l}\text { Mean stool output/ } \\
\text { mean intake of } \\
\text { solution }\end{array}$ & & \\
\hline Guiraldes et al & $48 / 49$ & $126(64)$ & $2 \cdot 0$ & $0 \cdot 30$ & $14(219)$ & $0 \cdot 21$ \\
\hline Kenya $e t a l^{1+}$ & $49 / 50$ & $103(31)$ & $3 \cdot 3$ & $0 \cdot 48$ & $3(35)$ & Zero \\
\hline Dutta $e t a l^{12}$ & $33 / 37$ & $103(55)$ & 1.9 & $0 \cdot 60$ & $17(145)$ & $0 \cdot 32$ \\
\hline Bhan et al" & $33 / 31$ & $77(58)$ & $1 \cdot 3$ & 0.49 & $10(161)$ & $0 \cdot 29$ \\
\hline El Mougi et al ${ }^{15}$ & $26 / 25$ & $245(129)^{\star}$ & 1.9 & 0.72 & $82(1115)$ & 0.04 \\
\hline Mohan et al ${ }^{13}$ & $23 / 23$ & $110(69)$ & 1.6 & & $22(340)$ & $0 \cdot 14$ \\
\hline
\end{tabular}

*The reported SD $(25 \cdot 3)$ was very low in relation to the large observed difference in stool output; we assumed that the reported SD values were actually SEs and revised the SDs accordingly.

immediately before treatment with oral rehydration salts solution began - that is, after the completion of any intravenous treatment for severe dehydration. However, in no trial was it stated when patients with severe dehydration were randomised and outcome measurements initiated - that is, before or after initial intravenous rehydration. Thus it was unclear whether the first 24 hour measurement of stool output began when intravenous rehydration was started or when oral rehydration salts solution was first given, as should have been the case.

In one study patients were randomised irrespective of age, but were stratified into arbitrary age groups during analysis. ${ }^{8}$ Ideally, such stratification should have been part of the randomisation plan. Stratification during analysis was also done in two other studies (Moechtar et al), ${ }^{9}$ but this was based on aetiology and so was unavoidable.

\section{Exclusion from analysis}

Pragmatic analysis according to intention to treat requires that all randomised patients continue to be monitored and that their data be included in the analysis. Nevertheless, in seven trials (Guiraldes et $a l)^{68913-15} 1-15 \%$ of randomised patients were excluded from the analysis (table I), either because they were considered to be "treatment failures" (usually because additional intravenous treatment was required) or because they had been randomised in error. In two trials that used a permuted block $^{10}$ or factorial design (Alam et al) it seems that some patients were randomised but not reported on, as the numbers specified in the different treatment groups differed appreciably. The reasons for these differences were not stated.

\section{Analysis and internal consistency of outcome data}

Whereas all studies reported stool output and oral rehydration salts solution intake during the first 24 hours, few reported total stool output until diarrhoea stopped, and only seven studies reported the duration of diarrhoea. Our analysis therefore focused largely on stool output during the first 24 hours. The following results for the first 24 hours are reported: mean (standard deviation) stool output (in $\mathrm{g}$ or $\mathrm{ml} / \mathrm{kg}$ body weight) for patients randomised to WHO oral rehydration salts solution; the ratio of mean stool output to its standard deviation; the ratio of mean stool output to mean intake of WHO oral rehydration salts solution; and the mean reduction in stool output (in $\mathrm{g}$ or $\mathrm{ml} / \mathrm{kg}$ ) for patients given rice oral rehydration salts solution compared with those given WHO oral rehydration salts solution, and the variance of that value.

Tables II, III, and IV show the mean (SD) stool output (in $\mathrm{g}$ or $\mathrm{ml} / \mathrm{kg}$ ) during the first 24 hours for patients in each study who were randomised to receive WHO oral rehydration salts solution. Whether the data were for adults with cholera or with cholera-like diarrhoea (severe dehydrating diarrhoea, clinically resembling that associated with cholera but from which Vibrio cholerae 01 was not isolated) (table II), children with cholera or cholera-like diarrhoea (table III), or children with only acute non-cholera diarrhoea (table IV), the ratios of mean to standard deviation for stool output were roughly constant, averaging 1.6 and ranging (with one exception) from $1 \cdot 2$ to $2 \cdot 5$. This regularity indicates the need for logarithmic transformation; however, no study reported logarithmically transformed data or performed calculations on that scale. This finding also provides a criterion for judging the internal consistency of key outcome data. By this 
criterion one trial seems to be atypical with a ratio of $3 \cdot 3,{ }^{14}$ twice the mean value reported in other studies. Even more extreme was the ratio of 10 from the data reported in another study. ${ }^{15}$ We suspected confusion between standard error and standard deviation in this study, and therefore table IV shows what we believe to be the correct standard deviation for this trial, a value similar to those in the other studies.

Tables II, III, and IV also show a second measure by which to assess the internal consistency of trial datanamely, the ratio of mean stool output to mean intake of WHO oral rehydration solution. Mean stool output averages about two thirds of mean oral rehydration salts solution intake. By this criterion one trial seems to be atypical, ${ }^{10}$ the mean stool output being almost $50 \%$ greater than the mean intake of oral rehydration salts solution (table III). In the analyses that follow, two studies ${ }^{1014}$ have been excluded (that is, zero weighted) for the reasons mentioned above.

\section{SUBSTANTIVE RESULTS}

The results of the analysis of stool output and intake of oral rehydration salts solutions during the first 24 hours have been grouped into three sets according to the patient's age and aetiology of diarrhoea, as shown in tables II, III, and IV. For the duration of diarrhoea all data have been combined, but comparisons in patients with suspected cholera who received tetracycline before diarrhoea stopped have been zero weighted (table V).

Adults with cholera or cholera-like diarrhoea-Table II shows the weights assigned to each of the five comparisons in this set. By using these weights the estimated mean stool output for patients given WHO oral rehydration salts solution was $170 \mathrm{ml} / \mathrm{kg}$. For patients given rice oral rehydration salts solution this was reduced by a mean of $58 \mathrm{ml} / \mathrm{kg}(36 \%, 95 \%$ confidence interval 28 to $44 \%$ ).

Children with cholera or cholera-like diarrhoea-Table III shows the weights assigned to each of the five comparisons in this set. One study ${ }^{15}$ was zero weighted for reasons described above. With those weights the estimated mean stool output for patients given the WHO oral solution was $178 \mathrm{ml} / \mathrm{kg}$. For patients given the rice solution this was reduced by a mean of $48 \mathrm{ml} / \mathrm{kg}$ (32\%, 19\% to $45 \%)$.

Children with non-cholera diarrhoea-In this set of six comparisons, one study ${ }^{14}$ was zero weighted for reasons described above (table IV). By using the weights calculated for the other five comparisons the estimated mean stool output for patients given the WHO solution was $107 \mathrm{ml} / \mathrm{kg}$. For patients given the rice solution this was reduced by a mean of $18 \mathrm{ml} / \mathrm{kg}(18 \% ; 6 \%$ to $30 \%)$. It is noteworthy that the estimated mean percentage reduction in stool output associated with the rice solution in the zero weighted study is outside the $95 \%$ confidence interval derived from the other five studies.

Overall reduction in stool output - The figure presents the percentage reduction in mean stool output (with

TABLE V - Duration of diarrhoea

\begin{tabular}{|c|c|c|c|c|c|}
\hline \multirow[b]{2}{*}{ Comparison } & \multirow{2}{*}{$\begin{array}{l}\text { No analysed } \\
\text { taking WHO/rice } \\
\text { solution }\end{array}$} & \multicolumn{2}{|c|}{ Treatment with WHO solution } & \multirow{2}{*}{$\begin{array}{l}\text { Mean reduction } \\
\text { (variance) duration of } \\
\text { diarrhoea with rice } \\
\text { solution }\end{array}$} & \multirow[b]{2}{*}{ Study weight } \\
\hline & & $\begin{array}{c}\text { Mean (SD) No of } \\
\text { patients }\end{array}$ & $\begin{array}{c}\text { Mean } \\
\text { duration/SD }\end{array}$ & & \\
\hline \multicolumn{6}{|c|}{ Adults with cholera } \\
\hline Moechtar et al (1) & $83 / 81$ & $39(11)$ & $3 \cdot 5$ & $2(3)$ & Zero \\
\hline Moechtar et al (2) & $12 / 14$ & $36(7)$ & $5 \cdot 1$ & $7(13)$ & Zero \\
\hline Alam et al (1) & $47 / 46$ & $86(22)$ & $3 \cdot 9$ & $9(26)$ & $0 \cdot 23$ \\
\hline Alam et al (2) & $42 / 47$ & $85(20)$ & $4 \cdot 2$ & $4(22)$ & $0 \cdot 27$ \\
\hline \multicolumn{6}{|c|}{ Children with cholera } \\
\hline Alam et al (3) & $24 / 24$ & $90(43)$ & $2 \cdot 1$ & $12(109)$ & 0.05 \\
\hline Patra $e t a l^{\circ}$ & $24 / 24$ & $43(22)$ & $2 \cdot 0$ & $13(36)$ & $0 \cdot 17$ \\
\hline \multicolumn{6}{|c|}{ Children without cholera } \\
\hline Kenya $e t a l^{14}$ & $49 / 50$ & $46(9)$ & $5 \cdot 1$ & $4(4)$ & Zero \\
\hline Dutta et al ${ }^{12}$ & $33 / 37$ & $79(37)$ & $2 \cdot 1$ & $10(67)$ & 0.09 \\
\hline El Mougi et al $l^{16}$ & $26 / 25$ & $34(12)$ & $2 \cdot 8$ & $6(31)$ & $0 \cdot 19$ \\
\hline
\end{tabular}

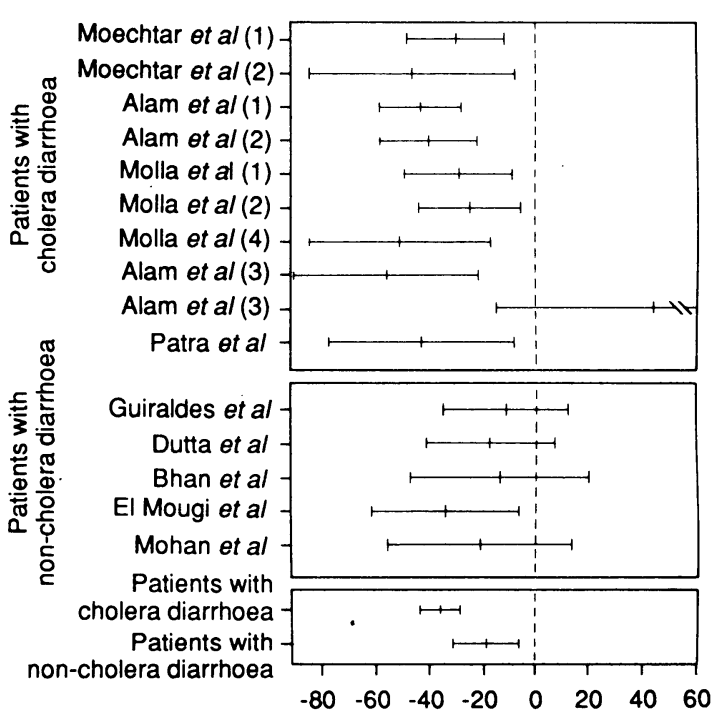

Percentage reduction in stool output

Mean percentage reduction in 24 hour stool output in individual studies of adults and children with cholera or cholera-like diarrhoea and children with non-cholera diarrhoea given rice oral rehydration salts solution. Pooled (weighted) estimates of percentage reduction in mean stool output (95\% confidence interval) for each group of studies are shown in shaded box

95\% confidence intervals) for patients treated with the rice solution in each of the comparisons considered in this overview, as well as the pooled (weighted) estimates of the percentage reduction in mean stool output for patients with cholera (adults and children) and without cholera (details of these calculations are not shown). The effect of the rice solution on stool output was significantly less in children with non-cholera diarrhoea than in children and adults with cholera or cholera-like diarrhoea $(95 \%$ confidence interval $3 \%$ to $31 \%$ for the difference in percentage reduction in stool output in patients with cholera or cholera-like diarrhoea $v$ patients with non-cholera diarrhoea).

Duration of diarrhoea-Data from six comparisons, including both adults and children with cholera (who had not received tetracycline before diarrhoea stopped) and acute non-cholera diarrhoea were considered for this analysis (table V). The estimated mean duration in patients given the WHO oral rehydration solution was 68 hours. For those given the rice solution the duration was reduced by a mean of eight hours $(12 \% ; 5 \%$ to $19 \%$ ). The $95 \%$ confidence interval excludes zero, indicating a modest but significant reduction in the duration of diarrhoea.

\section{Discussion}

Irrespective of their age, patients with cholera who were given rice oral rehydration salts solution had substantiall lower rates of stool loss than those who were given WHO oral rehydration salts solution. Stool volume was reduced by a mean of $48-58 \mathrm{ml} / \mathrm{kg}$ during the first 24 hours of treatment, which was $32-36 \%$ less output than for patients given the WHO solution. This presumably reflects the fact that a greater amount of glucose (and amino acids) is released when rice powder is fully digested than is present in the WHO solution. Assuming that glucose facilitated absorption of sodium proceeds on an equimolar basis, $50-80 \mathrm{~g} / \mathrm{l}$ of rice powder would release sufficient glucose and amino acids to promote the absorption of all the sodium (and water) in the rehydration solution and, in addition, reabsorption of at least part of the sodium (and water) secreted into the bowel as part of the diarrhoeal process, thus diminishing stool output. ${ }^{18}$ In contrast, the WHO solution contains only enough glucose $(20 \mathrm{~g} /$ 1) to promote the absorption of the sodium and water in 
the solution, thus leaving the rate of stool loss essentially unaffected..$^{19}$ The lower osmolarity of the rice solution (about $200 \mathrm{mmol} / \mathrm{l} v$ about $310 \mathrm{mmol} / \mathrm{l}$ ) would also enhance the intestinal absorption of water, but not of sodium..$^{20}$

In contrast with stool output in cholera patients, that in children with acute non-cholera diarrhoea was reduced by a mean of only $18 \mathrm{ml} / \mathrm{kg}$ during the first 24 hours of treatment with rice solution - that is, by $18 \%$ compared with that in patients given the WHO solution. The significantly smaller benefit of the rice solution for these patients apparently reflects a partial failure of the process described above. The likely explanations are that, at least in some patients, rice starch and protein were not fully digested, thus reducing the amount of glucose and amino acids available to promote sodium absorption; or released glucose was not fully absorbed; or both. Failure to digest rice powder fully could reflect reduced amylase or disaccharidase activities related to young age, malnutrition, or mucosal damage by the infective agent. ${ }^{21-23}$ Mucosal damage could also cause glucose malabsorption, which could exacerbate the rate of stool loss owing to the osmotic activity of unabsorbed glucose in the bowel lumen. If this occurred the adverse effect would be greater for rice oral rehydration salts solution owing to the greater amount of glucose released when rice starch is fully hydrolysed. This meta-analysis affords no insight into which of these mechanisms explains the reduced effect of rice oral rehydration salts on stool loss in patients with acute non-cholera diarrhoea.

The meta-analysis shows that treatment with rice solution reduces both the rate of stool loss and, to a lesser extent, the duration of diarrhoea, as compared with treatment with the WHO solution. Both of these variables independently affect the total output of diarrhoeal stool during the illness. Thus when both are reduced the percentage reduction in total stool output would be greater than the percentage reduction in either of the contributing measurements. This suggests that total output of diarrhoeal stool would be the most important clinical outcome measure when different oral rehydration salts formulations are compared. Unfortunately, this value was reported for only one study reviewed here ${ }^{6}$ and for another that compared a sorghum based oral rehydration salts solution with the WHO solution. ${ }^{24}$ In both studies the percentage reduction was greater in total stool output than in either the rate of stool loss or duration of diarrhoea.

The last point bears directly on whether the rice solution (or any other cereal based oral rehydration salts solution) would have sufficient advantage over the WHO solution to replace it in routine use at health facilities, especially for treating children with acute non-cholera diarrhoea, who represent the overwhelming majority of cases. The average $18 \%$ reduction in initial rate of stool loss, if applied to total stool output, is unlikely to justify the major effort and expense required to change over from glucose to precooked rice in the oral rehydration salts formulation, especially in developing countries. A crude estimation showed that the current cost of commercially prepared oral rehydration salts based on precooked rice would be for each one litre packet about three times the cost of the standard packet of WHO oral rehydration salt packet. On the other hand, if the effect on total stool output is appreciably greater, owing to a concurrent shortening of illness, a change in oral rehydration salts formulation might be justified. This requires further study. In the meantime the current data show that rice oral rehydration salts solution has enough advantage over the WHO oral rehydration salts solution to justify its use in patients with cholera, where this is convenient.

1 Avery ME, Synder JD. Oral therapy for acute diarrhoea. The underused simple solution. N Engl f Med 1990;323:891-4

2 Pierce NF, Barnwell JC, Mitra RC, Caranasos GJ, Keimowitz RI, Mondal A, et al. Effect of intragastric glucose-electrolyte infusion upon water and electrolvte balance in Asiatic cholera. Gastroenterology 1968;55:333-43.

3 Hirschhorn N, Kinzie JL, Sachar DB, Northrup RS, Taylor JO, Ahmad SZ, $e t$ al. Decrease in net stool output in cholera during intestinal perfusion with al. Decrease in net stool output in cholera during intestinal perf
glucose containing solutions. N Engl f Med 1968:279:176-80.

4 Mahalanabis D, Sack RB, Jacobs B, Mondal A, Thomas J. Use of an oralglucose-electrolyte solution in the treatment of pediatric cholera: a controlled
gate glucose-electrolyte solution in the treatment of pediatric cholera: a controlled
study. Fournal of Tropical Pediatrics and Environmental Child Health study. Journal of Tropical Pediatrics and Environmental Child Health
1974;20:82-7.

5 Sack DA, Chowdhury AMAK, Eusof A, Ali MA, Merson MH, Islam S, et al. Oral hydration in rotavirus diarrhoea: a double-blind comparison of sucrose with glucose-electrolyte solution. Lancet 1978;ii:280-3.

6 Patra FC, Mahalanabis D, Jalan KN, Sen A, Banerjee P. Is oral rice electrolyte solution superior to glucose electrolyte solution in infantile diarrhoea? Arch Dis Child 1982;57:910-2.

7 Molla AM, Sarker A, Molla A, Khatoon M, Greenough WB III. Rice-based oral rehydration therapy in acute diarrhoea: a superior therapy and a medium for calorie supplementation. In: Eeckels RE, Ransome-Kuti O, Kroonenberg CC, eds. Chid health in the tropics: sixth Nutricia-Cow and Gate symposium, Leuwen, 18-21 October 1983. Dordrecht, The Netherlands: symposium, Leuwen,

8 Molla AM, Ahmed SM, Greenough WB III. Rice-based oral rehydration solution decreases the stool volume in acute diarrhoea. Bull WHO solution decreases

9 Alam AN, Sarker SA, Molla AM, Rahaman MM, Greenough W'B III. Hydrolysed wheat-based oral rehydration solution for acute diarrhoea. Arch Dis Child 1987;62:440-4.

10 Molla AM, Nath SK, Molla A, Khatun M. Food based oral rehydration salt solution for acute childhood diarrhoea. Lancet 1989;ii:429-31.

11 Bhan MK, Ghai OP, Khoshoo V, Vasudev AS, Bhatnagar NK, Arora R, et al. Efficacy of mung bean and pop rice based oral rehydration solutions in comparison with the standard glucose electrolyte solution. I Pediatr Gastroenterol Nutr 1987;6:392-9.

12 Dutta P, Dutta D, Bhattacharya SK, Sinha AK, Mondal BC, Pal SC. Comparative efficacy of three different oral rehydration solutions for the treatment of dehydrating diarrhoea in children. Indian F Med Res 1988;87: 229-33.

13 Mohan M, Antony TJ, Malik S, Mathur M. Rice powder oral rehydration solution as an alternative to glucose electrolvte solution. Indian 7 Med Res $1988 ; 87: 234-9$.

14 Kenya PP, Odongo HW, Oundo G, Waswa K, Muttunga J, Molla AM, et al. Cereal based oral rehydration solutions. Arch Dis Child 1989;64: 1032-5.

15 El Mougi M, Hegazi E, Galal O, El Akkad N, El-Abhar A, Nour N, et al. Controlled clinical trial on the efficacy of rice powder-based oral rehydration solution on the outcome of acute diarrhoea in infants. $\mathcal{F}$ Pediatr Gastroenterol Nutr 1988;7:572-6.

16 Mohan M, Sethi JS, Daral TS, Sharma M, Bhargava SK, Sachdev HPS. Controlled clinical trial of rice powder and glucose rehydration solutions as oral therapy for acute dehydrating diarrhoea in infants. $\mathcal{I}$ Pediatr Gastroenterol Nutr 1986;5:423-7.

17 Patra FC, Mahalanabis D, Jalan KN, Maitra TK, Sen A, Banerjee P. A controlled clinical trial of rice and glycine-containing oral rehydration solution for acute diarrhoea in children. I Diarrhoeal Dis Res 1986;4:16-9.

18 Patra FC, Mahalanabis D, Jalan KN, Sen A, Baneriee P. In search of a super solution: controlled clinical trial of a glycine-glucose oral rehydration solution: controlled clinical trial of a glycine-glucose oral rehy
solution in infantile diarrhoea. Acta Paediatr Scand 1984;73:18-21.

19 Hirschhorn $N$. The treatment of acute diarrhoea in children: an historical and physiological perspective. Am f Clin Nutr 1980;33:637-63.

20 Wapnir RA, Zdanowicz M, Teichberg S, Lifshitz F. Alanine stimulation of water and sodium absorption in a model of secretory diarrhoea. $\mathcal{F}$ Pediatr Gastroenterol Nutr 1990;10:213-21.

21 Lebenthal E, Lev R, Lee PC. In: Lebenthal E, ed. Textbook of gastroenterology and nutrition in infancy. New York: Raven Press, 1981:149-65.

22 Lebenthal E, Heitlinger L, Lee PC, Nord KS, Hodge C, Brooks SP, George D. Corn syrup sugars: in vitro and in vivo digestibility and clinical tolerance in acute diarrhoea of infancy. F Pediatr 1983;103:29-34.

23 Vesikari T, Isolauri E. Glycine supplemented oral rehydration solutions for diarrhoea. Arch Dis Child 1986;61:372-6.

24 Lepage P, Hitimana DG, Vand Goethem C, Ntahorutaba M, Nsengumuremyi F. Food based oral rehydration salt solution for acute childhood diarrhoea. Lancet 1989;ii:868.

(Accepted 19 November 1991) 